\title{
Mapping of QTL for Color of Noodle Dough Sheet in a Doubled Haploid Population
}

\author{
H. Kang ${ }^{1,2}$, C. S. Kang ${ }^{2}$, H. Kim² \& C. S. Park ${ }^{1,3}$ \\ ${ }^{1}$ Department of Crop Science and Biotechnology Chonbuk National University, Jeonju, Korea \\ ${ }^{2}$ National Institute of Crop Science, RDA, Suwon, Korea \\ ${ }^{3}$ Institute of Agricultural Sciences and Technology, Chonbuk National University, Jeonju, Korea \\ Correspondence: C. S. Park, Department of Crop Science and Biotechnology Chonbuk National University, \\ Jeonju 561-756, Korea. E-mail: pcs89@jbnu.ac.kr
}

$\begin{array}{lc}\text { Received: February 24, } 2015 & \text { Accepted: March 25, } 2015 \text { Online Published: April 15, } 2015 \\ \text { doi:10.5539/jas.v7n5p182 } & \text { URL: http://dx.doi.org/10.5539/jas.v7n5p182 }\end{array}$

\begin{abstract}
This study was conducted for identification of the quantitative trait loci (QTL) associated with the color of flour and noodle dough sheets for the production of white salted noodles by analysis of a doubled haploid population from a cross between Korean wheat cultivars carrying different color values for the flour and noodle dough sheets. The DH population was evaluated in replicated field trials in 2011 and 2012 in upland conditions in Iksan, Korea. The color differences were measured as CIE-LAB L, $a$ and $b$ values. Xgwm 190 located on chromosome 5D explained $13.3 \%-22.8 \%$ of the phenotypic variation in the color of flour over the average of two years. Xgwm 190 also explained $11.8 \%$ and $24.1 \%$ of the phenotypic variation for the $L$ and $b$ values of the noodle dough sheets for the average of two years, respectively. Xbarc 81 and $X g w m 133$ accounted for $7.9 \%$ and $9.8 \%$ of the phenotypic variation in the $b$ value of flour produced in 2012 and the noodle dough sheets from flour produced in 2011, respectively. The putative marker for flour and noodle dough sheet color, Xgwm190, was applied to validate the relationship between genotypes of 24 Korean wheat cultivars. Fourteen of the Korean wheat cultivars contained genotype $a$, which represented homozygous to Keumkang at Xgwm190, showed lower $L$ values of the flour and noodle dough sheets (91.6 and 83.5, respectively) than genotype $b$ (93.6 and 85.1, respectively), which represented homozygous to Olgeuru at Xgwm190. Xgwm190 could be used for the selection of wheat lines with bright color in Korean wheat breeding programs.
\end{abstract}

Keywords: wheat, quantitative trait loci (QTL), color, flour, noodle dough sheet

\section{Introduction}

The color of flour is a main consideration of determining the acceptability in noodles to consumers, albeit noodles are produced in wide ranges of color. Noodle color is mainly affected by the color of flour due to the simple formula and processing compared to bread-baking (Huo, 2001; Fu, 2008). There are two distinct categories of noodles based on the type of salt $(\mathrm{Fu}, 2008)$. White salted noodles, which are made from dough with flour, water and salt content based on the flour weight, are widely consumed in Korean and Japan (Fu, 2008). Bright color, ranging from white to creamy white, is desirable for white salted noodles, whereas a bright yellow color is preferable for yellow alkaline noodles (Huo, 2001; Fu, 2008).

Flour color includes complex attributes, such as pigments of starchy endosperm, pericarp and pigments in the aleurone of wheat grain, as well as the flour extraction ratio, particle size, protein and ash content, and microbial contamination (Miskelly, 1984; Mares \& Campbell, 2001). The brightness of flour decreases with increase of the particle size as well as the protein, ash, damaged starch and tailing starch content, which causes dull color in white salted noodles (Huo, 2001; Fu, 2008). Slow discoloration is also important because the noodles are often stored raw for several days prior to cooking, during which discoloration can occur due to the effects of polyphenol oxidase, which is generally derived from the seed coat (Hatcher \& Kruger, 1993; Fuerst et al., 2006). Therefore, execution of the correct milling procedures and inclusion of an appropriate range of protein content is important to maintain the brightness of white salted noodles (Huo, 2001; Fu, 2008). The factors related to the color of flour and the resulting noodles are genetically quantitative, often influenced by the environment and 
exhibit high genotype $\times$ environment interaction (Mares \& Campbell, 2001; Davies \& Berzonsky, 2003; Graybosch et al., 2004; Zhao et al., 2013).

Major QTL associated with the color of flour have been found on all chromosome arms using recombinant inbred lines, DH populations and the genetic resources of common wheat (Triticum aestivum L.) (Mares \& Campbell, 2001; Kuchel et al., 2006; Zhang et al., 2009a, 2009b; Sadeque \& Turner, 2010a; Bordes et al., 2011; Li et al., 2011; Tsilo et al., 2011; Roncallo et al., 2012; Zhao et al., 2013). The QTL for yellow pigments, polyphenol oxidase and carotenoid genes were also found to be associated with the flour and noodle color (Marles \& Campbell, 2001; Raman et al., 2007; He et al., 2008; Zhang et al., 2009b; Sadeque \& Turner, 2010b; Crawford et al., 2011; Martin et al., 2011; Crawford \& Francki, 2013a, 2013b).

Korean wheat breeding programs have recently focused on the quality improvement of white salted noodles, and over 30 cultivars have been developed since the 1970s. However, few cultivars have been used in the production of white salted noodles because the consumers prefer cultivars which provide bright creamy color and soft texture of the cooked noodles. The objective of this study was to perform QTL analysis for the color of flour and noodle dough sheets using doubled haploid population crosses Keumkang and Olgeuru to gain an understanding of the genetic basis for improvement of the color in Korean wheat breeding programs. Keumkang, developed in 1997, is the most commonly grown cultivar in Korea, possessing good milling quality and medium dough strength, but its color is a little dull (Nam et al., 1998). Olgeuru is a soft red cultivar used for making white salted noodles, and has a brighter color than Keumkang (Nam et al., 1995).

\section{Materials and Methods}

\subsection{Plant Materials}

A population of 114 doubled haploid lines was derived from $F_{1}$ plants of Keumkang and Olgeuru crosses using the wheat $\times$ maize system according to the procedures of Inagaki and Mujeeb-Kazi (1995) at International Maize and Wheat Improvement Center (CIMMYT, El Batan, Mexico). The doubled haploid lines were grown at the Crop Experimental Farm of the National Institute of Crop Science, RDA (Iksan, Korea), for seed multiplication in 2009. Field trials were performed in randomized complete blocks with 3 replicates in upland conditions from 2011 to 2012 in Iksan, Korea. Twenty-four Korean wheat cultivars were also cultivated under the same conditions as the DH population in 2013. The seeds were sown on October 25, and each plot consisted of three 4 $\mathrm{m}$ rows spaced $25 \mathrm{~cm}$ apart. The plots were combine-harvested on June 20. Fertilizer was applied at 5: 7: 5 $\mathrm{kg} / 10 \mathrm{a}(\mathrm{N}: \mathrm{P}: \mathrm{K})$ before sowing. Weeds, insects and disease were stringently controlled. No supplemental irrigation was applied. The grains from each plot were dried using forced air driers and bulked from replications to provide grains for color measurement.

\subsection{Color of Flour and Noodle Dough Sheets}

Wheat was milled with a Bühler experimental mill, according to the AACC International Approved Method 26-31.01. (2010). Two kilograms of wheat were conditioned overnight to reach $15 \%$ moisture content and then milled at a feed rate of $100 \mathrm{~g} / \mathrm{min}$ with roll settings of 8 and 5 in break rolls, and 4 and 2 in reduction rolls. Noodle dough sheets for white salted noodles were prepared with $34 \%$ water absorption of the noodle dough according to the description of Park and Baik (2002). Flour (100 g, 14\% mb) was mixed with a determined amount of sodium chloride solution in a pin mixer (National Mfg. Co., USA) for 4 min, with a head speed of 86 rpm. The concentration of sodium chloride solution for making noodles was adjusted to $2.0 \%$ sodium chloride. Crumbly dough was passed through the rollers of a noodle machine (Ohtake Noodle Machine Mfg. Co., Japan) running at $65 \mathrm{rpm}$ with a 3-mm gap to form a dough sheet, and then the dough sheet was folded and put through the sheeting rollers. The folding and sheeting were repeated twice. The dough sheet was rested for $1 \mathrm{hr}$ and then put through the sheeting rollers three times at progressively decreasing gaps of $2.40,1.85$ and $1.30 \mathrm{~mm}$. After the last sheeting, the dough sheet was cut into $5 \times 10 \mathrm{~cm}$ portions for measurement of the color. The flour and noodle dough sheet color was measured by colorimeter (CM-2002, Minolta Camera, Osaka, Japan) with an 11-mm measurement aperture. The color differences were recorded as CIE values, including $L$ (lightness), $a$ (redness-greenness), and $b$ (yellowness-blueness).

\subsection{PCR Conditions}

Leaf tissue was collected from a single plant of each doubled haploid line after germination for two weeks, snap-frozen in liquid nitrogen and stored at $-80{ }^{\circ} \mathrm{C}$ until needed. Genomic DNA was extracted from the young leaf tissue (100 mg) using a genomic DNA prep kit (Solgent Co., Korea), according to the manufacturer's instructions. DNA was quantified by Biodrop (Biodrop Ltd, UK). A total of 592 simple sequence repeats (SSRs) were used to survey the polymorphisms between the parents, and 140 polymorphic markers were used to 
genotype the DH populations. The PCR reactions were performed in a total volume of $15 \mu \mathrm{L}$ containing $100 \mathrm{ng}$ genomic DNA, 1X PCR buffer, $1.5 \mathrm{mM} \mathrm{MgCl} 2,0.2 \mathrm{mM}$ dNTPs, 1 unit Taq DNA polymerase, and $0.2 \mathrm{ug} / \mathrm{ul}$ each primer. After an initial denaturation at $94{ }^{\circ} \mathrm{C}$ for $5 \mathrm{~min}, 10$ cycles (decrease of $1{ }^{\circ} \mathrm{C}$ per cycle) were performed for $1 \mathrm{~min}$ at $94{ }^{\circ} \mathrm{C}, 1 \mathrm{~min}$ at $63{ }^{\circ} \mathrm{C}$, and $1 \mathrm{~min}$ at $72{ }^{\circ} \mathrm{C}$, followed by 35 cycles of $1 \mathrm{~min}$ at $94{ }^{\circ} \mathrm{C}, 1 \mathrm{~min}$ at $55^{\circ} \mathrm{C}$, and $1 \mathrm{~min}$ at $72{ }^{\circ} \mathrm{C}$ with a final extension at $72{ }^{\circ} \mathrm{C}$ for $10 \mathrm{~min}$. The PCR products were analyzed with the QIAxcel Advanced system using a 12-capillary QIAxcel DNA high resolution cartridge (Qiagen Co., USA).

\subsection{Statistical Analysis}

Statistical analysis of the data was performed by SAS software (SAS Institute, NC, USA), utilizing the Fisher's least significant difference test (LSD), analysis of variance (ANOVA) and pair-wise t-test. Analysis of variance was conducted using the general linear model (GLM) procedure, with the genotype $\times$ year component as the error term. The GLM procedure was used for the randomized complete block (RCB) analysis. Sources of variation in the model were considered to be fixed effects. PROC GLM was used to estimate the relative contribution of the loci tested for the measured traits of the $114 \mathrm{DH}$ lines. The mean of each marker allele type was compared by one-way ANOVA, and differences were considered to be significant at $P<0.05$, unless otherwise specified. The pair-wise $t$ test at $P=0.05$ was conducted to compare means when $\mathrm{F}$ tests were significant. Pearson correlations between pairs of traits were determined from the least square means of DH lines separately at each year and over all environments, using the Corr procedure. Heritability $\left(h^{2}\right)$ on a progeny mean basis was estimated from RCM analysis using the formula $h^{2}=1-(M 2 / M 1)$, proposed by Knapp et al. (1985), where $M 1$ is the mean square of genotype and $M 2$ is the mean square for genotype by environment interaction (G $\times \mathrm{E})$ in $\mathrm{DH}$ populations grown in different year.

\subsection{QTL Analysis}

A genetic map of the DH population using 140 SSR markers identified a partial genetic map spanning 2,340.7 $\mathrm{cM}$ over all 21 chromosomes. Individual maps for the initial QTL detection were constructed using MapDisto (http://mapdisto.free.fr). Composite interval mapping (CIM) analysis (Zeng, 1993, 1994) was performed using QTL Cartographer v2.5 for Windows (Wang et al., 2012), based on a model 6, Forward and Backward Regression method. The walking speed for all QTL was $2.0 \mathrm{cM}$, and the probability in stepwise regression was $P$ $<0.001$. Centimorgan units were calculated using the Kosambi mapping function. Empirical logarithm of the odds (LOD) value thresholds were estimated using 1,000 permutations at an experiment-wise $P<0.01$ (Churchill \& Doerge, 1994). The LOD scores for declaring QTLs were significant at 3.0. The additive value and coefficient of determination $\left(R^{2}\right)$, based on the partial correlation of the putative QTL with the trait adjusted for cofactors in the multilocus model, were estimated based on the most significant dataset.

\section{Results}

Keumkang showed lower $L$ value and higher $a$ and $b$ values of the flour than Olgeuru, but no significant differences were found in the color of the noodle dough sheet between the parental cultivars, because it was prepared with fixed water absorption in this study (Table 1). The frequency distributions of the color of the flour and noodle dough sheets were continuous, and transgressive segregation was observed in the DH populations based on the overall mean of two years (Figure 1). The year explained for the largest proportion of the variation among flour and noodle dough sheet color, although the color may have been influenced by both genotype and genotype by environment interactions (Table 2 ). However, the estimated heritability $\left(h^{2}\right)$ of the flour and noodle dough sheet colors for in the DH population was $0.45 \%-0.93 \%$. The $L$ value of flour was negatively correlated with the $a$ and $b$ values and a positive correlation was observed between the $a$ and $b$ values of flour (Table 3). The $L$ value of the noodle dough sheet was also significantly correlated with the $a$ and $b$ values. In addition, the $L$ and $b$ values of the flour positively correlated with those of the noodle dough sheet, but no significant relationship was found for the $a$ value between the parental cultivars. 

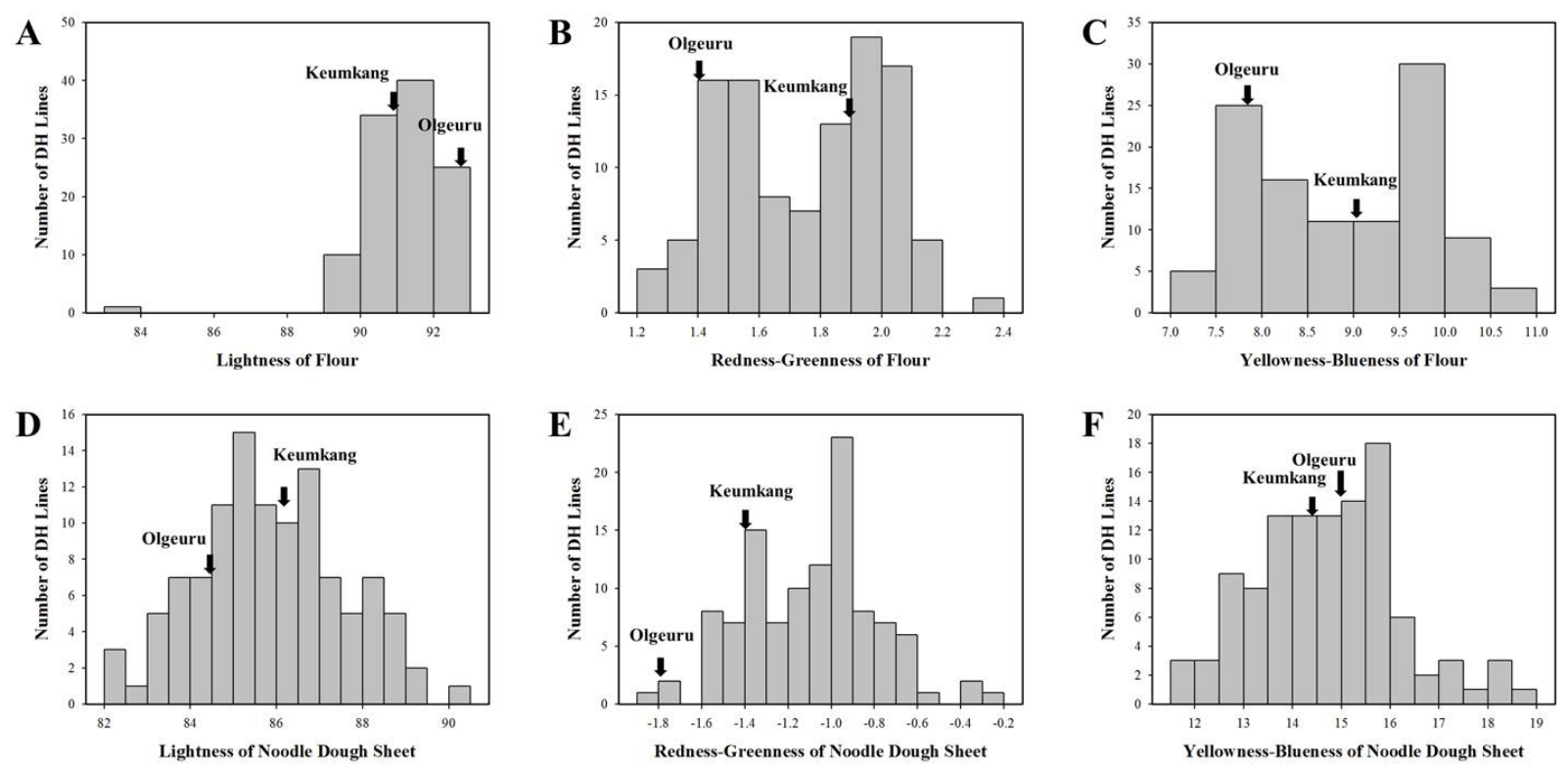

Figure 1. Frequency distributions of the lightness (A and D), redness-greenness (B and E) and yellowness-blueness ( $\mathrm{C}$ and $\mathrm{F}$ ) of flour and noodle dough sheets for white salted noodles, prepared from $114 \mathrm{DH}$ populations. Arrows indicate mean values of the parental cultivars

Table 1. Means and ranges of flour and noodle dough sheet color for white salted noodles prepared from $114 \mathrm{DH}$ populations grown two years in upland conditions

\begin{tabular}{llllllll}
\hline \multirow{2}{*}{ Traits $^{*}$} & \multicolumn{2}{c}{ Parents $^{\dagger}$} & & \multicolumn{3}{c}{ DH population } \\
\cline { 2 - 3 } & Keumkang & Olgeuru & & Mean \pm SD & Range & $h^{2 \ddagger}$ \\
\hline Flour- $L$ & $91.0 \mathrm{~b}$ & $92.8 \mathrm{a}$ & & $91.1 \pm 1.2$ & $83.0-92.7$ & 0.45 \\
Flour- $a$ & $1.9 \mathrm{a}$ & $1.4 \mathrm{~b}$ & & $1.8 \pm 0.3$ & & $1.2-2.4$ & 0.86 \\
Flour- $b$ & $9.1 \mathrm{a}$ & $7.9 \mathrm{~b}$ & & $8.9 \pm 1.0$ & $7.0-11.0$ & 0.93 \\
Noodle- $L$ & $84.5 \mathrm{a}$ & $85.8 \mathrm{a}$ & & $85.9 \pm 1.7$ & $82.2-90.1$ & 0.45 \\
Noodle- $a$ & $-1.1 \mathrm{a}$ & $-1.8 \mathrm{a}$ & & $-1.1 \pm 0.3$ & & $-1.8--0.3$ & 0.46 \\
Noodle- $b$ & $14.4 \mathrm{a}$ & $14.9 \mathrm{a}$ & & $14.7 \pm 1.5$ & & $11.7-18.8$ & 0.60
\end{tabular}

Note. ${ }^{*} L, a$ and $b$ of flour and noodle indicate the lightness, redness-greenness and yellowness-blueness of flour and noodle dough sheets for white salted noodles, respectively.

${ }^{\dagger}$ Values followed by the same letters are not significantly different at $P<0.05$.

${ }^{*}$ Heritability $\left(h^{2}\right)$ was estimated from the variance traits of the $114 \mathrm{DH}$ populations. 
Table 2. Analysis of variance of flour and noodle dough sheet colors for white salted noodles, prepared from 114 DH populations grown two years in upland conditions

\begin{tabular}{|c|c|c|c|c|c|c|c|}
\hline \multirow{4}{*}{ Source of Variation } & \multirow{4}{*}{$\mathrm{df}$} & \multicolumn{6}{|c|}{$F$-values } \\
\hline & & \multicolumn{6}{|c|}{ CIE value $^{*}$} \\
\hline & & \multicolumn{3}{|c|}{ Flour } & \multicolumn{3}{|c|}{ Noodle dough sheet } \\
\hline & & $\bar{L}$ & $a$ & $b$ & $\bar{L}$ & $a$ & $b$ \\
\hline$\overline{\operatorname{Year}(\mathrm{Y})}$ & 1 & 21.92 & 677.98 & 4458.74 & 4445.00 & 5220.92 & 4385.68 \\
\hline$P$ & & $<0.001$ & $<0.001$ & $<0.001$ & $<0.001$ & $<0.001$ & $<0.001$ \\
\hline Genotypes (G) & 113 & 7.89 & 191.17 & 968.46 & 56.81 & 23.01 & 60.01 \\
\hline$P$ & & $<0.001$ & $<0.001$ & $<0.001$ & $<0.001$ & $<0.001$ & $<0.001$ \\
\hline$G \times Y$ & 113 & 4.34 & 27.29 & 69.32 & 31.29 & 12.52 & 23.76 \\
\hline$P$ & & $<0.001$ & $<0.001$ & $<0.001$ & $<0.001$ & $<0.001$ & $<0.001$ \\
\hline
\end{tabular}

Note. ${ }^{*} L, a$ and $b$ of flour and noodle indicate the lightness, redness-greenness and yellowness-blueness of the flour and noodle dough sheets for white salted noodles, respectively.

Table 3. Pearson correlation coefficients among color of flour and noodle dough sheets for white salted noodles prepared from $114 \mathrm{DH}$ populations grown two years in upland conditions

\begin{tabular}{|c|c|c|c|c|c|}
\hline Parameters $^{*}$ & Flour- $L$ & Flour- $a$ & Flour- $b$ & Noodle- $L$ & Noodle- $a$ \\
\hline Flour- $a$ & -0.46 & & & & \\
\hline$P$ & $<0.001$ & & & & \\
\hline Flour- $b$ & -0.52 & 0.84 & & & \\
\hline$P$ & $<0.001$ & $<0.001$ & & & \\
\hline Noodle- $L$ & 0.31 & -0.48 & -0.56 & & \\
\hline$P$ & $<0.01$ & $<0.001$ & $<0.001$ & & \\
\hline Noddle- $a$ & 0.01 & 0.07 & -0.13 & 0.37 & \\
\hline$P$ & $\mathrm{NS}^{\dagger}$ & NS & NS & $<0.001$ & \\
\hline Noodle- $b$ & -0.30 & 0.50 & 0.70 & -0.82 & -0.43 \\
\hline$P$ & $<0.01$ & $<0.001$ & $<0.001$ & $<0.001$ & $<0.001$ \\
\hline
\end{tabular}

Note. ${ }^{*} L, a$ and $b$ of flour and noodle indicate the lightness, redness-greenness and yellowness-blueness of the flour and noodle dough sheets, respectively.

${ }^{\dagger} \mathrm{NS}=$ not significant.

Two QTLs, Xbarc81 and Xgwm190, were found to be associated with the flour color, and were mapped to chromosomes 1B and 5D, respectively (Table 4 and Figure 2). Xgwm 190 explained 25.5\%, 47.6\% and 24.4\% of the phenotypic variation $\left(R^{2}\right)$ with LOD scores of 4.6, 9.1 and 9.1 for $L, a$ and $b$, respectively, for the flour from wheat grown in 2012. Xgwm 190 also explained $22.2 \%, 13.3 \%$ and $22.8 \%$ of the $R^{2}$ with LOD scores of 5.2, 4.9 and 9.0 for each color value of flour in the average of two years. Xbarc 81 accounted for $7.9 \%$ of the $R^{2}$ with LOD scores of 3.4 for the $b$ value of flour from wheat grown in 2012. Xgwm190 had negative additive effects on the $L$ value of flour, but positive additive effects on the $a$ and $b$ values. These results indicate that the Keumkang alleles reduced the lightness and increased the redness-greenness and blueness-greenness of the flour from the DH populations, demonstrating decrease of the $L$ value of flour by 0.6 and increase of the $a$ and $b$ values of 0.2 and 0.5 , respectively, in the average of two years. 
Table 4. QTL for color of flour and noodle dough sheets for white salted noodles using composite interval mapping in $114 \mathrm{DH}$ populations grown two years in upland conditions

\begin{tabular}{|c|c|c|c|c|c|}
\hline Traits*/Marker & Chr. & $\mathrm{LOD}^{\dagger}$ & $R^{2}(\%)^{\ddagger}$ & Additive effect $^{\S}$ & Environmen \\
\hline \multicolumn{6}{|l|}{ Flour- $L$} \\
\hline Xgwm190 & $5 \mathrm{D}$ & 4.6 & 25.5 & -0.7 & 2012 \\
\hline Xgwm190 & $5 \mathrm{D}$ & 5.2 & 22.2 & -0.6 & Mean \\
\hline \multicolumn{6}{|l|}{ Flour-a } \\
\hline Xgwm190 & $5 \mathrm{D}$ & 9.1 & 47.6 & 0.2 & 2012 \\
\hline Xgwm190 & $5 \mathrm{D}$ & 4.9 & 13.3 & 0.1 & Mean \\
\hline \multicolumn{6}{|l|}{ Flour- $b$} \\
\hline Xbarc81 & 1B & 3.4 & 7.9 & 0.3 & 2012 \\
\hline Xgwm190 & $5 \mathrm{D}$ & 9.1 & 24.4 & 0.5 & 2012 \\
\hline Xgwm190 & $5 \mathrm{D}$ & 9.0 & 22.8 & 0.5 & Mean \\
\hline \multicolumn{6}{|l|}{ Noodle- $L$} \\
\hline Xgwm190 & $5 \mathrm{D}$ & 5.3 & 17.3 & -0.8 & 2011 \\
\hline Xgwm 190 & $5 \mathrm{D}$ & 4.3 & 11.8 & -0.6 & Mean \\
\hline \multicolumn{6}{|l|}{ Noodle- $a$} \\
\hline Xgwm133 & $6 \mathrm{~B}$ & 3.0 & 9.8 & 0.1 & 2011 \\
\hline \multicolumn{6}{|l|}{ Noodle- $b$} \\
\hline Xgwm190 & $5 \mathrm{D}$ & 6.5 & 26.6 & 1.0 & 2011 \\
\hline Xwmc 83 & $7 \mathrm{~A}$ & 3.4 & 23.9 & -0.9 & 2012 \\
\hline Xgwm190 & $5 \mathrm{D}$ & 4.6 & 24.1 & 0.7 & Mean \\
\hline
\end{tabular}

Note. ${ }^{*} L, a$ and $b$ of flour and noodle indicate the lightness, redness-greenness and yellowness-blueness of the flour and noodle dough sheets, respectively.

'Logarithm of the odds.

The ratio of phenotypic variation $\left(R^{2}\right)$ explained by the overall mean of the dataset. The mean of each QTL was compared by one-way ANOVA at significance levels of $P \leq 0.001$.

${ }^{\S}$ Additive effects of allele substitution. The units are those of the corresponding traits. Positive signs indicate that the Keumkang allele increased the quantitative trait, and vise-versa. 
$1 \mathrm{~B}$

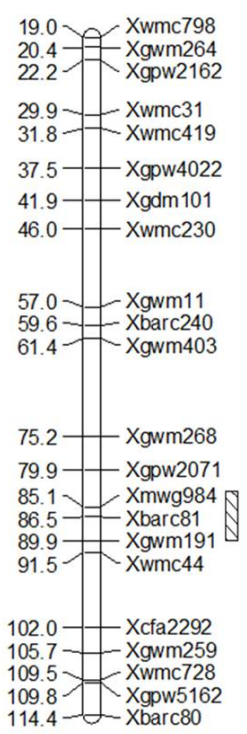

5D

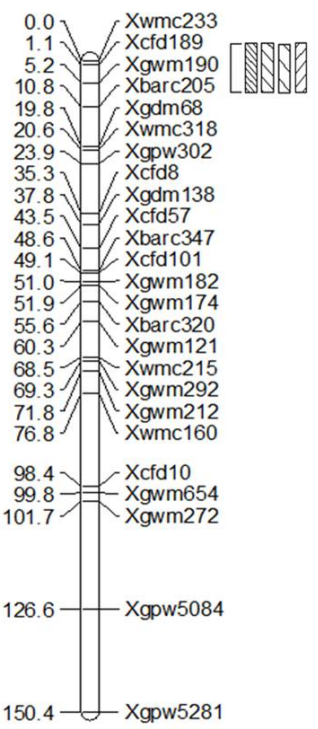

6B

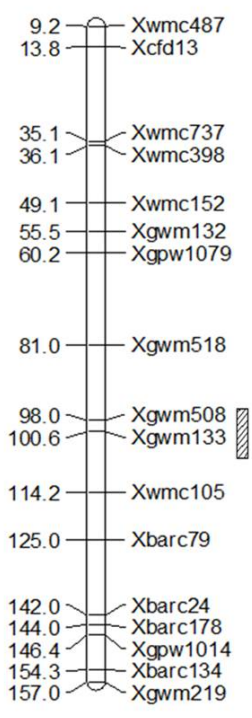

7A

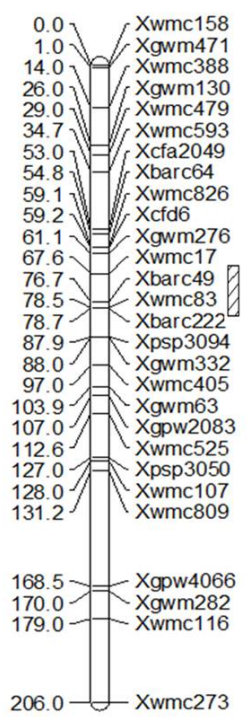

$$
\begin{array}{|lll|}
\hline \text { Flour } L^{*} & \text { एका Flour } a^{*} & \text { Flour } b^{*} \\
\text { Noodle } L^{*} & \text { पा Noodle } a^{*} & \text { पा Noodle } b^{*}
\end{array}
$$

Figure 2. Linkage maps for the color of flour and noodle dough sheets for white salted noodles on chromosome 1B, 5D, 6B and 7A in $114 \mathrm{DH}$ populations. Markers are indicated on the right, with genetic distances (cM) on the left. Different stripes of the markers indicate the color of flour and noodle dough sheets for white salted noodles, for which the symbols are located at the bottom of the figure

Xgwm 190 was also found to be associated with the $L$ and $b$ values of the noodle dough sheets for white salted noodles for flour produced in 2011/2012 and the average of the two years. Xgwm190 explained 17.3\% and 11.8 $\%$ of the $R^{2}$, with LOD scores of 5.3 and 4.3 for the $L$ value of the noodle dough sheet made with flour produced in 2011 and for the average of the two years, respectively. $X g w m 190$ also explained $26.6 \%$ and $24.1 \%$ of the $R^{2}$, with LOD scores of 6.5 and 4.6 for the $b$ value of noodle dough sheets produced from flour of wheat grown in 2012 and the average of two years, respectively. The additive effects of Xgwm190 in $L$ and $b$ of noodle dough sheets were the same as those of flour. Another two QTLs found to be associated with the $a$ and $b$ values of the noodle dough sheet, Xgwm 133 and Xwmc83, were mapped to chromosomes 6B and 7A, respectively. Xgwm133 explained $9.8 \%$ of the $R^{2}$ with LOD scores of 3.0 for the $a$ value of the noodle dough sheets made from flour of wheat grown in 2011. Xwmc83 explained $23.9 \%$ of the $R^{2}$ with LOD scores of 3.4 for the $b$ value of noodle dough sheets produced from flour made in 2012. Similar to the other QTLs, Xgwm133 had a positive additive effect on the $a$ value of noodle dough sheet, whereas $X w m c 83$ had a negative additive effect on the $b$ value of noodle dough sheet.

The range of color in the Korean wheat cultivars was 90.6 - 94.2 for the $L$ value, $-1.4--0.7$ for the $a$ value and $6.9-12.0$ for the $b$ value in flour, with $L$ values of $82.7-85.8, a$ values of $-1.1-0.2$ and $b$ values of $11.8-18.3$ for the noodle dough sheet for white salted noodles (Table 5). The 24 Korean wheat cultivars showed genotypes $a$ and $b$ at Xgwm 190, a putative QTL for flour and noodle dough sheet color (Figure 3). Fourteen of the Korean wheat cultivars contained genotype $a$, which represented homozygous to Keumkang at Xgwm190, while the remaining 10 had genotype $b$, which indicated homozygous to Olgeuru. The Korean wheat cultivars carrying genotype $b$ showed higher $L$ values of both the flour and noodle dough sheets (93.6 and 85.1, respectively) than those with genotype $a$ (91.6 and 83.5, respectively, Figure 4). No significant differences were found in the $a$ and $b$ values of flour and noodle dough sheets. 
Table 5. Color of flour and noodle dough sheets for white salted noodles according to the genotype of Xgwm190 in 24 Korean wheat cultivars grown in upland conditions

\begin{tabular}{|c|c|c|c|c|c|c|c|}
\hline \multirow{3}{*}{ Cultivar } & \multirow{3}{*}{$X g w m 190^{*}$} & \multicolumn{6}{|c|}{ CIE value $^{\dagger}$} \\
\hline & & \multicolumn{3}{|c|}{ Flour } & \multicolumn{3}{|c|}{ Noodle dough sheet } \\
\hline & & $L$ & $a$ & $b$ & $L$ & $a$ & $b$ \\
\hline Alchan & $a$ & 91.8 & -0.9 & 9.3 & 83.5 & -0.4 & 17.1 \\
\hline Anbaek & $a$ & 90.6 & -1.2 & 10.8 & 83.2 & -0.5 & 16.5 \\
\hline Baekjoong & $b$ & 93.6 & -1.1 & 9.9 & 85.8 & -0.8 & 13.5 \\
\hline Cheonggye & $b$ & 93.7 & -1.0 & 8.2 & 85.0 & -0.8 & 16.3 \\
\hline Dahong & $a$ & 92.6 & -1.1 & 8.3 & 83.8 & -0.8 & 16.8 \\
\hline Dajoong & $a$ & 91.5 & -1.1 & 10.8 & 84.0 & -0.4 & 16.6 \\
\hline Geuru & $a$ & 91.4 & -1.1 & 10.2 & 84.2 & -0.6 & 16.8 \\
\hline Gobun & $b$ & 93.5 & -1.0 & 9.9 & 84.8 & -0.3 & 17.2 \\
\hline Goso & $b$ & 94.2 & -1.1 & 7.6 & 85.7 & -0.4 & 14.7 \\
\hline Hanbaek & $a$ & 90.8 & -0.7 & 9.7 & 82.7 & 0.2 & 12.1 \\
\hline Jeokjoong & $b$ & 93.3 & -1.1 & 10.1 & 84.7 & -0.8 & 14.3 \\
\hline Joa & $a$ & 93.0 & -1.0 & 8.2 & 83.7 & -1.0 & 15.6 \\
\hline Jokyung & $a$ & 91.4 & -1.1 & 10.1 & 83.9 & -0.8 & 14.8 \\
\hline Jonong & $a$ & 92.2 & -0.7 & 6.9 & 83.3 & -0.2 & 11.8 \\
\hline Jopoom & $a$ & 91.7 & -1.1 & 9.8 & 83.1 & -0.5 & 15.5 \\
\hline Keumkang & $a$ & 91.1 & -0.8 & 9.6 & 83.3 & -0.3 & 15.5 \\
\hline Namhae & $b$ & 93.9 & -1.0 & 8.2 & 85.2 & -0.7 & 16.3 \\
\hline $\mathrm{Ol}$ & $a$ & 92.3 & -1.2 & 9.3 & 83.9 & -1.1 & 18.3 \\
\hline Olgeuru & $b$ & 94.2 & -1.0 & 7.8 & 85.4 & -1.0 & 16.3 \\
\hline Suan & $b$ & 93.3 & -0.8 & 8.8 & 85.4 & -0.1 & 13.2 \\
\hline Sukang & $a$ & 90.6 & -1.4 & 12.0 & 82.7 & -1.1 & 17.3 \\
\hline Tapdong & $a$ & 91.3 & -0.8 & 9.0 & 83.9 & 0.0 & 15.9 \\
\hline Uri & $b$ & 93.6 & -1.0 & 8.5 & 85.0 & -0.7 & 17.0 \\
\hline Younbaek & $b$ & 93.4 & -1.1 & 10.5 & 84.3 & -0.8 & 15.6 \\
\hline $\mathrm{LSD}^{*}$ & - & 0.1 & 0.1 & 0.1 & 0.4 & 0.6 & 0.6 \\
\hline
\end{tabular}

Note. ${ }^{*} a$, and $b$ represent homozygous to Keumkang and Olgeuru, respectively.

${ }^{\dagger} L, a$ and $b$ of flour and noodle indicate the lightness, redness-greenness and yellowness-blueness of the flour and noodle dough sheets, respectively.

theast significant difference $(P<0.05)$.

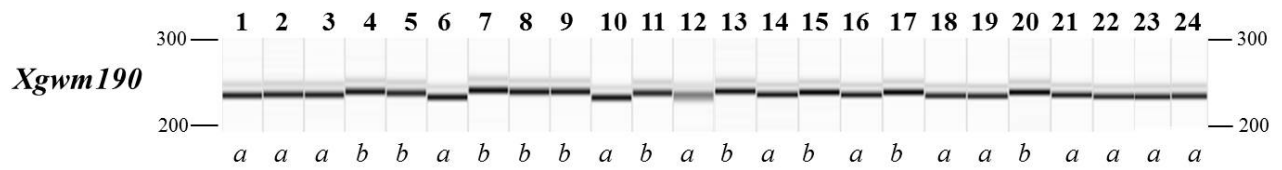

Figure 3. PCR products produced from QIAxcel system of QTL, Xgwm190, in 24 Korean wheat cultivars. 1, Ol; 2, Geuru; 3, Dahong; 4, Cheongkye; 5, Suan; 6, Tapdong; 7, Namhae; 8, Uri; 9, Olgeuru; 10, Alchan; 11, Gobun; 12, Keumkang; 13, Baekjoong; 14, Sukang; 15, Jeokjoong; 16, Hanbaek;17, Goso; 18, Anbaek; 19, Jopoom; 20 , Younbaek; 21, Jonong; 22, Jokyung; 23, Dajoong; 24, Joa. $a$ and $b$ represent homozygous to Keumkang and Olgeuru, respectively 

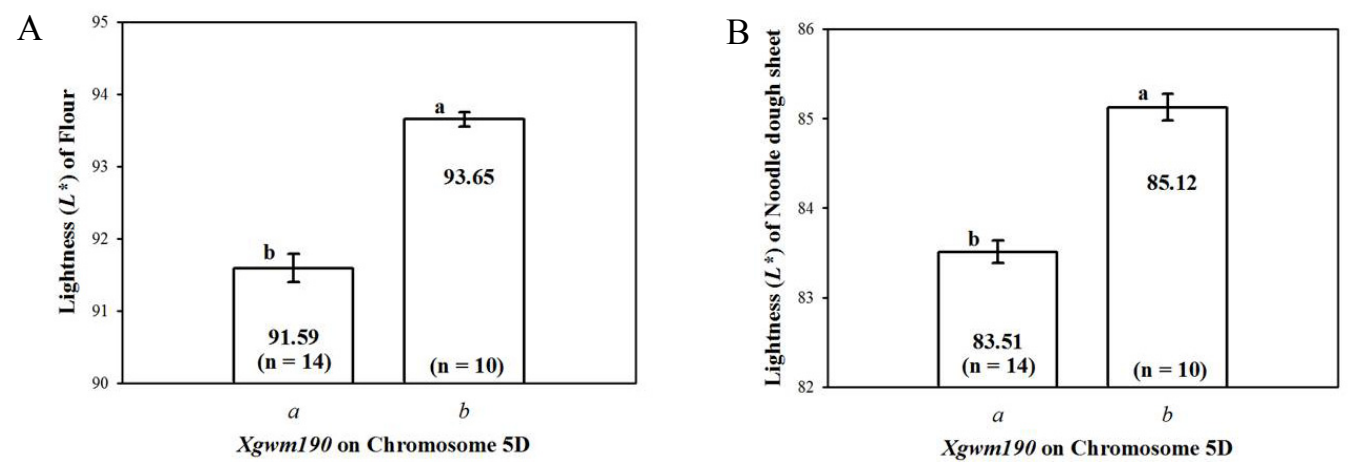

Figure 4. Difference in the lightness of flour (A) and noodle dough sheets for white salted noodles (B) according to the genotype of Xgwm 190 in 24 Korean wheat cultivars. Each bar represents the mean \pm standard error, while $a$ and $b$ represent homozygous to Keumkang and Olgeuru, respectively. Bars with different letters above are significantly different at $p<0.05$

\section{Discussion}

Color readings are usually expressed as CIE (Commission Internationale I'Eclairage) values, which are record as $L$ value for lightness, $a$ value for redness-greenness and $b$ value for yellowness-blueness (Sun et al., 2002). Theoretically, pure white flour should have values of zero for both $a$ and $b$, and one hundred for the $L$ value (Sun et al., 2002). Therefore, flour or noodle dough sheets with low values of $L$ and high positive values of $a^{*}$ would result in a gray and dull color (Sun et al., 2002). Zhang et al. (2009b) proposed that high $L$ and low $b$ values of flour are very important to improve the noodle color for white salted noodles because the $b$ value of noodle dough sheets for white salted noodles was significantly correlated with the $L$ and $b$ values of the wheat flour. Flour color is known to be influenced by both the bran and endosperm color of the grain (Baik et al., 1995; Mares \& Campbell, 2001). The color of noodle dough sheets is also been affected by the physicochemical properties of the flour used, including flour yield, ash, protein, damaged starch content and protein quality (Feillet et al., 2000; Huo, 2001; Fu, 2008). These traits are also associated with polyphenol oxidase, which catalyzes the oxidation of phenols to produce dark-colored products, which are related to the discoloration of noodle dough (Baik et al., 1995; Feillet et al., 2000). There is generally a high correlation between the $b$ value of flour and the yellow pigment content, which is primarily influenced by the levels of carotenoids (Mares \& Campbell, 2001). Several enzymes in the carotenoid biosynthetic pathway, such as catalase (Cat3-A1), lycopene-e-cyclase $(e-L Y C)$, phytoene synthase (Psy) and Zeta ( $\zeta$ )-carotene desaturase (ZDS), have been functionally associated with variation in the $b$ value of flour (He et al., 2008; Howitt et al., 2009; Crawford et al., 2011; Zhang et al., 2011; Crawford \& Francki, 2013a, 2013b).

Water absorption of the noodle dough affects the noodle color and sheeting, while the cutting and drying of noodles becomes difficult when there is deviation of the water absorption by over $2 \%$ from the optimum (Oh et al., 1986). The optimum water absorption has been determined by experienced personnel based on the handling properties of noodle dough in the industry, and a fixed absorption for making noodle dough has been used in a laboratory to evaluate noodle-making quality of wheat flours (Park \& Baik, 2002). As shown in our previous report, Keumkang had higher protein, damaged starch content, SDS-sedimentation volume and water absorption of the mixograph than Olgeuru (Ahn et al., 2014). The color of the flour and noodle dough sheets are influenced by both genotype and environment, including factors such as growing conditions at the grain filling stage, milling process and the manufacturing process of noodles (Parker et al., 1998; Graybosch et al., 2004; Zhang et al., 2009). Heritability of the $L$ and $b$ values of flour and noodle dough sheets for white salted noodles was also found in DH lines of Australian wheat (Mares \& Campbell, 2001). The flour and noodle dough sheet color showed high heritability and low genotype by environment interactions, which could allow useful QTL detection power in a small sample of environments (Narasimhamoorthy et al., 2006).

Major QTL associated with the color of flour have been detected on 17 chromosomes for the $L$ value of flour: $1 \mathrm{~A}, 1 \mathrm{~B}, 2 \mathrm{~A}, 2 \mathrm{~B}, 2 \mathrm{D}, 3 \mathrm{~A}, 3 \mathrm{~B}, 3 \mathrm{D}, 4 \mathrm{~B}, 4 \mathrm{D}, 5 \mathrm{~A}, 5 \mathrm{~B}, 5 \mathrm{D}, 6 \mathrm{~A}, 6 \mathrm{~B}, 7 \mathrm{~B}$ and 7D; on 15 chromosomes for the $a$ value of flour: $1 \mathrm{~A}, 1 \mathrm{~B}, 2 \mathrm{~A}, 2 \mathrm{~B}, 3 \mathrm{~A}, 3 \mathrm{D}, 4 \mathrm{~A}, 4 \mathrm{~B}, 4 \mathrm{D}, 5 \mathrm{~A}, 5 \mathrm{~B}, 5 \mathrm{D}, 6 \mathrm{~A}, 6 \mathrm{~B}$ and $7 \mathrm{~B}$; and on 14 chromosomes for the $b$ value of flour: 1A, 1B, 1D, 2A, 2D, 3A, 3B, 4A, 4B, 4D, 5B, 5D, 6A, 6D, 7A, 7B and 7D (Mares \& Campbell, 2001; Kuchel et al., 2006; Howitt et al., 2009; Zhang et al., 2009a, 2009b; Li et al., 2011; Tsilo et al., 2011; Crawford \& Francki, 2013b; Zhao et al., 2013). The Xbarc81 and Xgwm190 QTLs detected herein were 
localized at 86.5 on chromosome $1 \mathrm{~B}$ and at $5.2 \mathrm{cM}$ on chromosome 5D. Zhang et al. (2009a) reported one flanking QTL, $X c f d 2226-X w m c 765$, detected at $8.0 \mathrm{cM}$ on chromosome 5D for the $L$ value of flour and two flanking QTLs, Xbarc372-Xwmc412.2 and Xwmc215-Xgdm63, detected at $0.1 \mathrm{cM}$ and $9.0 \mathrm{cM}$ on chromosomes $1 \mathrm{~B}$ and 5D for the $a$ value of flour, respectively, in a Chinese DH population. These two flanking markers located on chromosome 5D were closely located with the Xgwm190 QTL detected in this study. Tsilo et al. (2011) reported one QTL, Xbarc130, detected at $0.0 \mathrm{cM}$ on chromosome 5D that affected the $L$ and $b$ values of flour in recombinant inbred lines of hard red spring lines. This marker was near the hardness $(\mathrm{Ha})$ locus on chromosome 5D, which is known to influence endosperm texture and the tightly linked puroindoline genes, Pina and Pinb, functioning as the $\mathrm{Ha}$ locus (Morris, 2002). Li et al. (2011) reported one flanking QTL, Xbarc161-Xbarc144, detected at $4.0 \mathrm{cM}$ on chromosome 5D for the whiteness of flour in recombinant inbred lines of Chinese wheat, although QTLs with significant relation to flour color were not found on chromosomes 1B and 5D. Zhang et al. (2009b) reported that the rye secalin marker Secl, which identified the 1RS rye chromosome and was associated with 1B/1R wheat-rye translocation, demonstrated an association with the $b$ value of flour and was significantly related to the yellow pigment of wheat flour made from Chinese recombinant inbred lines. Zhao et al. (2013) also reported two flanking QTLs, Xwmc419b-Xcfd20 and Xubc880d-Xswes 119a, detected on chromosome 1B which affected the $b$ value of flour from Chinese recombinant inbred lines. They also reported that one flanking QTL, Xswes555b-Xswes558b, and two flanking QTLs, Xswes1061-Xswes340a and XwPt5505-Xgwm182, detected on chromosome 5D affected the $L$ and $a$ values of the flour, respectively.

Mares and Campbell (2001) reported that several QTLs detected on chromosomes 1B, 2B, 3B, 5B and 7A in DH populations of Australian wheat lines affected the $L$ and $b$ values of noodle dough sheets for white salted noodles. Zhang et al. (2009b) reported two flanking QTLs, Sec 1-HVM23 and Xwmc809-YP7A, detected on chromosome 1B and 7A, respectively, related to the color of noodle dough sheets for Chinese white salted noodles. This flanking marker was localized near the distal end of chromosome 7A, but Xwmc83 detected herein was localized at $78.5 \mathrm{cM}$. A QTL for the color of noodle dough sheets for white salted noodles was located on chromosome 5D in this study, while QTLs for the $L$ and $b$ values of noodle dough sheets for yellow alkaline noodles were previously detected on chromosomes 5B, 5D and 7AL in DH populations of Canadian wheat lines (McCartney et al., 2006). Sadeque and Turner (2010b) found a major QTL for the $L$ value of alkaline noodles on chromosome $2 \mathrm{~A}$, with additional QTLs on chromosomes 1A, 1B and 7A. The discoloration of Asian noodles is mainly influenced by polyphenol oxidase activity, which is controlled by two major genes, Ppo-A1 and Ppo-D1, located on chromosome 2A and 2D (Martin et al., 2011). More specific molecular markers should be applied in Korean wheat breeding programs to improve the color of noodle dough sheets for white salted noodles. The discoloration of the noodle dough sheets and yellow pigments in the flour and noodles should also be considered to improve the acceptance of noodles in the market.

Increasing the brightness of flour and the end-use products has been the most important criteria in Korea, as well as other countries. However, it is a laborious, time-consuming and high-cost process to measure the color of flour and end-use products because large quantities of grains should be milled. Color related traits of flour and the end-use products have generally been evaluated on the advanced stages of breeding populations. Therefore, it is important to accurately predict the color to allow selection of wheat lines with bright color at the early stages of breeding programs. The putative QTL, Xgwm190, could be helpful to select wheat lines with bright color in the Korean wheat breeding population, although validation lines are limited and further fine mapping is needed for application of color-improving traits of flour and end-use products in Korean wheat breeding programs.

\section{Acknowledgements}

This work was carried out with the support of the "Cooperative Research Program for Agriculture Science \& Technology Development (Project title: Establishment of quality criteria for high uniformity in end-use of Korean wheat cultivars, Project No. PJ011009), Rural Development Administration, Republic of Korea.

\section{References}

AACC International. (2010). Approved Methods of Analysis (11th ed., Methods 26-31.01). AACCI: St. Paul, MN, USA.

Ahn, J. H., Kang, C.-S., Jeung, J.-U., Baik, B.-K., Pena, R. J., \& Park, C. S. (2014). Effect of allelic variations at the Glu-D1, Glu-A3, Glu-B3 and Pinb-D1 loci on flour characteristics and bread loaf volume. International Food Research Journal, 21, 1177-1185.

Baik, B.-K., Czuchajowska, Z., \& Pomeranz, Y. (1995). Discoloration of dough for oriental noodles. Cereal Chemistry, 72, 198-205. 
Bordes, J., Ravel, C., Le Gouis, J., Lapierre, A., Charmet, G., \& Balfourtier, F. (2011). Use of a global wheat core collection for association analysis of flour and dough quality traits. Journal of Cereal Science, 54, 137-147. http://dx.doi.org/10.1016/j.jcs.2011.03.004

Churchill, G. A., \& Doerge, R. W. (1994). Empirical threshold values for quantitative trait mapping. Genetics, 138, 963-971.

Crawford, A. C., \& Francki, M. G. (2013a). Chromosomal location of wheat genes of carotenoid biosynthesis pathway and evidence for a catalase gene on chromosome 7A functionality associated with flour $\mathrm{B}^{*}$ colour variation. Molecular Genetics and Genomics, 288, 483-493. http://dx.doi.org/10.1007/s00438-013-0767-3

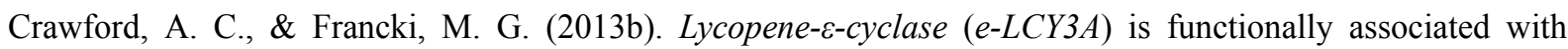
quantitatively trait loci for flour $\mathrm{b}^{*}$ colour on chromosome $3 \mathrm{~A}$ in wheat (Triticum aestivum L.). Molecular Breeding, 31, 737-741. http://dx.doi.org/10.1007/s11032-012-9812-x

Crawford, A. C., Stefanova, K., Lambe, W., McLean, R., Wilson, R., Barclay, I., \& Francki, M. G. (2011). Functional relationships of phytoene synthase 1 alleles on chromosome 7A controlling flour colour variation in selected Australian wheat genotypes. Theoretical and Applied Genetics, 123, 95-108. http://dx.doi.org/10.1007/s00122-011-1569-9

Davies, J., \& Berzonsky, W. A. (2003). Evaluation of spring wheat quality traits and genotypes for production of Cantonese Asian noodles. Crop Science, 43, 1313-1319. http://dx.doi.org/10.2135/cropsci2003.1313

Feillet, P., Autran, J. C., \& Vernière, C. L. (2000). Pasta brownness: An assessment. Journal of Cereal Science, 32, 215-233. http://dx.doi.org/10.1006/jcrs.2000.0326

Fu, B. X. (2008). Asian noodles: History, classification, raw materials, and processing. Food Research International, 41, 888-902. http://dx.doi.org/10.1016/j.foodres.2007.11.007

Fuerst, E. P., Anderson, J. V., \& Morris, C. F. (2006). Delineating the role of polyphenol oxidase in the darkening of alkaline wheat noodles. Journal of Agricultural and Food Chemistry, 54, 2378-2384. http://dx.doi.org/10.1021/jf0526386

Graybosch, R., Ames, N., Baenziger, P. S., \& Peterson, C. J. (2004). Genotypic and environmental modification of Asian noodle quality of hard winter wheats. Cereal Chemistry, 81, 19-25. http://dx.doi.org/10.1094/CCHEM.2004.81.1.19

Hatcher, D. W., \& Kruger, J. E. (1993). Distribution of polyphenol oxidase in flour millstreams of Canadian common wheat classes milled to three extraction rates. Cereal Chemistry, 70, 51-55.

He, X. Y., Zhang, Y. L., He, Z. H., Wu, Y. P., Xiao, Y. G., Ma C. X., \& Xia, X. C. (2008). Characterization of phytoene synthase 1 gene (Psyl) located on common wheat chromosome 7A and development of a functional marker. Theoretical and Applied Genetics, 116, 213-221. http://dx.doi.org/10.1007/s00122-007-0660-8

Hou, G. (2001). Oriental noodles. Advances in Food and Nutrition Research, 43, 141-193. http://dx.doi.org/10.1016/S1043-4526(01)43004-X

Howitt, C. A., Cavanagh, C. R., Bowerman, A. F., Cazzonelli, C., Rampling, L., Mimica, J. L., \& Pogson, B. J. (2009). Alternative splicing, activation of cryptic exons and amino acid substitutions in carotenoid biosynthetic genes are associated with lutein accumulation in wheat endosperm. Functional and Integrative Genomics, 9, 363-376. http://dx.doi.org/10.1007/s10142-009-0121-3

Knapp, S. J., Stroup, W. W., \& Ross, W. M. (1985). Exact confidence intervals for heritability and heritability on $\begin{array}{lllll}\text { a progeny mean } & \text { basis. Crop }\end{array}$ http://dx.doi.org/10.2135/cropsci1985.0011183X002500010046x

Inagaki, M. N., \& Mujeeb-Kazi, A. (1995). Comparison of polyhaploid production frequencies in crosses of hexaploid wheat with maize, pearl millet and sorghum. Breeding Science, 45, 157-161.

Kuchel, H., Langridge, P., Mosionek, L., Williams, K., \& Jefferies, S. P. (2006). The genetic control of milling yield, dough rheology and baking quality of wheat. Theoretical and Applied Genetics, 112, 1487-1495. http://dx.doi.org/10.1007/s00122-006-0252-z

Li, W.-H., Liu, W., Liu, L., You, M.-S., Liu, G.-T., \& Li, B.-Y. (2011). QTL mapping for wheat flour color with additive, epistatic, and QTL $\times$ environmental Interaction effects. Agricultural Sciences in China, 10, 651-660. http://dx.doi.org/10.1016/S1671-2927(11)60047-3 
Mares, D. J., \& Campbell, A. W. (2001). Mapping components of flour and noodle color in Australian wheat. Australian Journal of Agricultural Research, 52, 1297-1309. http://dx.doi.org/10.1071/AR01048

Martin, J. M., Berg, J. E., Hofer, P., Kephart, K. D., Nash, D., \& Bruckner, P. L. (2011). Allelic variation of polyphenol oxidase genes impacts on Chinese raw noodle color. Journal of Cereal Science, 54, 387-39. http://dx.doi.org/10.1016/j.jcs.2011.08.003

McCartney, C. A., Somers, D. J., Lukow, O., Ames, N., Noll, J., Cloutier, S., ... McCallum, B. D. (2006). QTL analysis of quality traits in the spring wheat cross RL4452 × 'AC Domain'. Plant Breeding, 125, 565-575. http://dx.doi.org/10.1111/j.1439-0523.2006.01256.x

Miskelly, D. M. (1984). Flour components affecting paste and noodle color. Journal of the Science of Food and Agriculture, 35, 463-471. http://dx.doi.org/10.1002/jsfa.2740350417

Morris, C. F. (2002). Puroindolines: the molecular genetic basis of wheat grain hardness. Plant Molecular Biology, 48, 633-647. http://dx.doi.org/10.1023/A:1014837431178

Nam, J.-H., Ha, Y.-W., Park, M.-W., Lee, S.-Y., Sung, B.-R., Park, H.-H., ... Park, K.-G. (1995). Early maturing, semi-dwarf and high yielding and good quality new soft wheat variety "Olgeurumil". RDA Journal of Agricultural Science, 37, 126-130.

Nam, J.-H., Song, H.-S., Park, H.-H., Ha, Y.-W., Park, M.-W., Park, K.-H., ... Kim, D.-H. (1998). A new high milling, early maturing, semi-dwarf and white grain wheat variety "Keumkangmil” with good bread quality. RDA Journal of Agricultural Science, 40, 81-87.

Narasimhamoorthy, B., Gill, B. S., Fritz, A. K., Nelson, J. C., \& Brown-Guedira, G. L. (2006). Advanced backcross QTL analysis of a hard winter wheat $\times$ synthetic wheat population. Theoretical and Applied Genetics, 112, 787-796. http://dx.doi.org/10.1007/s00122-005-0159-0

Oh, N. H., Seib, P. A., Finney, K. F., \& Pomeranz, Y. (1986). Noodles. V. Determination of optimum water absorption of flour to prepare oriental noodles. Cereal Chemistry, 63, 93-96.

Park, C. S., \& Baik, B.-K. (2002). Flour characteristics related to optimum water absorption of noodle dough for making white salted noodles. Cereal Chemistry, 79, 867-873. http://dx.doi.org/10.1094/CCHEM.2002.79.6.867

Parker, G. D., Chalmers, K. J., Rathijen, A. J., \& Langgridge, P. (1998). Mapping loci associated with flour colour in wheat (Triticum aestivum L.). Theoretical and Applied Genetics, 97, 238-245. http://dx.doi.org/10.1007/s001220050891

Raman, R., Raman, H., \& Matin, P. (2007). Functional gene markers for polyphenol oxidase locus in bread $\begin{array}{lllll}\text { wheat (Triticum } & \text { aestivum } & \text { L.) } & \text { Molecular } & \text { Breeding, }\end{array}$ http://dx.doi.org/10.1007/s11032-006-9064-8

Roncallo, P. F., Cervigni, G. L., Jensen, C., Miranda, R., Carrera, A. D., Helguera, M., \& Echenique, V. (2012). QTL analysis of main and epistatic effects for flour color traits in durum wheat. Euphytica, 185, 77-92. http://dx.doi.org/10.1007/s10681-012-0628-x

Sadeque, A., \& Turner, M. A. (2010a). QTL Mapping of flour color in a hexaploid wheat doubled haploid population using diversity array technology. Thai Journal of Agricultural Science, 43, 103-108.

Sadeque, A., \& Turner, M. A. (2010b). QTL mapping of polyphenol oxidase (PPO) activity and yellow alkaline noodle (YAN) color components in an Australian hexaploid wheat population. Thai Journal of Agricultural Science, 43, 109-118.

Sun, X. D., Wang, L. K., Ren, H. B., \& Lan, J. (2002). The application of tristimulus colorimeter in the determination of flour color. Science and Technology of Cereals, Oils and Foods, 10, 31-33.

Tsilo, T. J., Hareland, G. A., Chao, S., \& Anderson, J. A. (2011). Genetic mapping and QTL analysis of flour color and milling yield related traits using recombinant inbred lines in hard red spring wheat. Crop Science, 51, 237-246. http://dx.doi.org/10.2135/cropsci2009.12.0711

Wang, S., Basten, C. J., \& Zeng, Z.-B. (2012). Windows QTL Cartographer 2.5. Retrieved from http://statgen.ncsu.edu/qtlcart/WQTLCart.htm

Zeng, Z. B. (1993). The theoretical basis for separation of multiple linked gene effects in mapping quantitative trait loci. Proc. Natl. Acad. Sci., 90, 10972-10976. http://dx.doi.org/10.1073/pnas.90.23.10972

Zeng, Z. B. (1994). Precision mapping of quantitative trait loci. Genetics, 136, 1457-1468. 
Zhang, C., Dong, C., He, X., Zhang, L., Xia, X., \& He, Z. (2011). Allelic Variants at the TaZds-D1 Locus on Wheat Chromosome 2DL and their Association with Yellow Pigment Content. Crop Science, 51, 1580-1590. http://dx.doi.org/10.2135/cropsci2010.12.0689

Zhang, K.-P., Chen, G.-F., Zhao, L., Liu, B., Xu, X.-B., \& Tian, J.-C. (2009a). Molecular genetic analysis of flour color using a doubled haploid population in bread wheat (Triticum aestivum L.). Euphytica, 165, 471-484. http://dx.doi.org/10.1007/s10681-008-9756-8

Zhang, Y., Wu, Y., Xiao, Y., He, Z., Zhang, Y., Yan, J., ... Ma, C. (2009b). QTL mapping for flour and noodle colour components and yellow pigment content in common wheat. Euphytica, 165, 435-444. http://dx.doi.org/10.1007/s10681-008-9744-Z

Zhao, Y., Sun, H.-Y., Wang, Y.-Y., Pu, Y.-Y., Kong, F.-M., \& Li, S.-S. (2013). QTL mapping for the color, carotenoids and polyphenol oxidase activity of flour in recombinant inbred lines of wheat. Australian Journal of Crop Science, 7, 328-337.

\section{Copyrights}

Copyright for this article is retained by the author(s), with first publication rights granted to the journal.

This is an open-access article distributed under the terms and conditions of the Creative Commons Attribution license (http://creativecommons.org/licenses/by/3.0/). 